\title{
Calidad bacteriológica del agua del humedal Gualí-Tres Esquinas, Funza, Cundinamarca
}

Bacteriological quality of the water of the Guali-Tres Esquinas Wetland, Funza, Cundinamarca

Sandra Mónica Estupiñán-Torres ${ }^{1}$, Anyi Jiobana Cepeda Ruge ${ }^{2}$, Adriana Marcela Hurtado Díaz ${ }^{3}$, Karen Dayana Vega Pinzón ${ }^{4}$

\section{Resumen}

Objetivo. Realizar el diagnóstico de la calidad bacteriológica del agua del Humedal GualíTres Esquinas, por medio de indicadores de aguas residuales (coliformes totales, Escherichia coli y Enterococcus spp). Métodos. Se tomaron catorce muestras de agua de diferentes puntos del humedal ( 7 en la zona Tres Esquinas y 7 en la zona del parque industrial Cofradía). El recuento de microorganismos se realizó por el método de filtración de membrana siguiendo el Standard Methods, los microrganismos fueron identificados mediante BBL Crystal. Resultados. El agua del Humedal Gualí-Tres Esquinas contiene un alto número de E.coli, coliformes totales y Enterococcus spp., lo que confirma la contaminación de origen fecal en todo el ecosistema, los recuentos más altos se encontraron en la zona parque industrial La Cofradía para coliformes totales y Enteroccocus spp. y en la zona de Tres Esquinas para E. coli.

Palabras claves: Humedales, indicadores de contaminación, coliformes, calidad del agua, filtración por membrana.

\footnotetext{
1. Grupo Calidad de aguas. Programa de Bacteriología y Laboratorio Clínico. Universidad Colegio Mayor de Cundinamarca. ORCID: http://orcid.org/0000-0002-6937-4567

2. Vitalis S.A.C.

ORCID: http://orcid.org/0000-0002-4853-2829

3. Idime de occidente.

ORCID: http://orcid.org/0000-0002-4426-517X

4. Hospital Militar Central.

ORCID: http://orcid.org/0000-0003-3783-8635

Correspondencia: sestupinan@unicolmayor.edu.co
}

https://doi.org/10.22490/24629448.3703 


\section{Abstract}

Objetive. To evaluate the bacteriological quality of the water of the wetland Gualí-Tres Esquinas, using residual waters indicators (total coliforms, Escherichia coli and Enterococcus). Methods. Fourteen water samples were taken from different points of the wetland (7 in the Tres Esquinas zone and 7 in the Cofradía industrial park zone). The count of microorganisms was made by the membrane filtration method following the Standard Methods, the microorganisms were identified by BBL Crystal. Results. The water of the Gualí-Tres Esquinas Wetland contains a high number of E. coli, total coliforms and Enterococcus spp., confirming fecal contamination throughout the ecosystem, the highest counts were found in the La Cofradía industrial park zone for total coliforms and Enteroccocus spp. and in the Tres Esquinas zone for E. coli.

Keywords: Wetlands, Pollution Indicators, Coliforms, Water Quality, Membrane Filtration..

\section{Introducción}

Los humedales son ecosistemas de suma importancia para las especies de flora y fauna. Además, tienen un papel fundamental en procesos como la generación del ciclo hídrico y el mejoramiento del aire. Todos estos eventos ayudan a mantener el equilibrio biológico en los ecosistemas. Estos procesos se ven afectados por la contaminación que se genera debido a diferentes causas como son los desechos de aguas residuales procedentes de sectores aledaños, las cuales están cargadas de sedimentos y materia orgánica, la eliminación inadecuada de basuras y la sobre-explotación de diferentes recursos, entre otros (1).

Los humedales han sufrido en los últimos años cambios a causa de las actividades humanas producto de la apropiación y uso de sus espacios públicos, tales como la utilización de tierras con fines agrícolas o ganaderos, la ampliación de zonas urbanas con fines industriales o de recreación y la alteración de los regímenes hidráulicos (2). Como consecuencia de estas acciones desmedidas se ha producido una alteración de la dinámica natural de las cuencas que reciben las aguas que alimentan a estos cuerpos hídricos y los cambios en la cobertura vegetal que aumentan la carga de sedimentos y modifican la capacidad de retención de las aguas (3).

La problemática del Humedal Gualí-Tres Esquinas comprende principalmente la contaminación debido al vertimiento de aguas residuales, basuras y desperdicios provenientes de la industria y de los habitantes del municipio de Funza, que llegan al humedal sin previo tratamiento. Además, 
actualmente este cuerpo hídrico se encuentra en un proceso acelerado de deterioro, especialmente por el desarrollo urbanístico e industrial en las áreas de ronda del mismo y por las actividades agropecuarias y ganaderas.

Desde el punto de vista hidrológico, el $\mathrm{Hu}-$ medal Gualí-Tres Esquinas tiene una gran importancia a nivel regional, ya que a este cuerpo amortigua las crecientes y almacena el agua proveniente de las zonas altas. Igualmente, es indispensable para la operación del Distrito de Riego y Drenaje de La Ramada, de la cual se benefician predios de Funza y Mosquera que se dedican a las actividades agropecuarias (4).

Desde el año 2014, el Humedal Gualí-Tres Esquinas fue declarado como área de protección por la Corporación Autónoma Regional de Cundinamarca (CAR), y desde ese momento se han adelantado varias acciones tendientes a la conservación de este ecosistema como la implementación de proyectos para su recuperación y posterior conservación que consisten en la limpieza del cuerpo hídrico y el control y vigilancia de los vertimientos de aguas residuales (5).

En el presente estudio se realizó el diagnóstico de la calidad bacteriológica del agua del Humedal Gualí-Tres esquinas, lo cual permitió hacer una determinación de su estado actual y contar con más información a fin de que se tomen medidas para disminuir los impactos en la salud del medio ambiente, de los habitantes del sector y de esta manera vigilar por la conservación de este cuerpo de agua.

\section{Materiales y métodos}

Se utilizaron para el estudio 14 muestras de agua del Humedal Gualí-Tres Esquinas, 7 del sector Tres Esquinas y 7 de las zonas de recuperación del espejo de agua, que han sido previamente tratadas por la Empresa Municipal de Acueducto Alcantarillado y Aseo de Funza (EMAAF). Los procesos de tratamiento consistieron en eliminación de material vegetal y limpieza del Humedal. Estas zonas de recuperación se encuentran en el parque industrial La Cofradía hacia el municipio de Siberia. 
Tabla 1. Coordenadas toma de muestra Zona Tres Esquinas y Parque Industrial La Cofradía.

\begin{tabular}{|c|c|c|c|}
\hline ZONA & $\begin{array}{l}\text { PUNTO DE } \\
\text { MUESTREO }\end{array}$ & \multicolumn{2}{|c|}{ COORDENADAS } \\
\hline \multirow{7}{*}{ TRES ESQUINAS } & 1 & 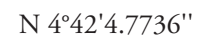 & $\mathrm{O} 74^{\circ} 12^{\prime} 5.2776^{\prime \prime}$ \\
\hline & 2 & 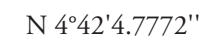 & O $74^{\circ} 12^{\prime} 5.292^{\prime \prime}$ \\
\hline & 3 & N 4º2'4.77" & O $74^{\circ} 12^{\prime} 5.2956^{\prime \prime}$ \\
\hline & 4 & N 4º' $42^{\prime} 7.5636^{\prime \prime}$ & O $74^{\circ} 12^{\prime} 3.9024^{\prime \prime}$ \\
\hline & 5 & N 4º $42^{\prime} 8.0532^{\prime \prime}$ & O $74^{\circ} 12^{\prime} 3.564^{\prime \prime}$ \\
\hline & 6 & N 4² $42^{\prime} 2.7396^{\prime \prime}$ & $\mathrm{O} 74^{\circ} 12^{\prime} 4.0752^{\prime \prime}$ \\
\hline & 7 & N 4ํํ' $2.754^{\prime \prime}$ & O $74^{\circ} 12^{\prime} 5.238^{\prime \prime}$ \\
\hline \multirow{7}{*}{$\begin{array}{c}\text { PARQUE } \\
\text { INDUSTRIAL LA } \\
\text { COFRADÍA }\end{array}$} & 8 & N 443'35.6664" & O $74^{\circ} 11^{\prime} 23.7768^{\prime \prime}$ \\
\hline & 9 & N 4²3'36.1668" & $\mathrm{O} 74^{\circ} 11^{\prime} 23.748^{\prime \prime}$ \\
\hline & 10 & N 443'35.04" & O $74^{\circ} 11^{\prime} 23.9064^{\prime \prime}$ \\
\hline & 11 & N 443'36.2892" & O $74^{\circ} 11^{\prime} 24.2412^{\prime \prime}$ \\
\hline & 12 & N 44'ㄱ' $36.8076^{\prime \prime}$ & O $74^{\circ} 11^{\prime} 24.3492^{\prime \prime}$ \\
\hline & 13 & N 4연 $37.1028^{\prime \prime}$ & O $74^{\circ} 11^{\prime} 24.558^{\prime \prime}$ \\
\hline & 14 & N 44'ㄱ' $37.8048^{\prime \prime}$ & O $74^{\circ} 11^{\prime} 25.0332^{\prime \prime}$ \\
\hline
\end{tabular}

La obtención de las muestras se realizó teniendo en cuenta la guía para la toma de muestras de agua del Ministerio de Salud de Colombia (Decreto 475 de 1998) (6) y las recomendaciones de Andreu y Camacho (7), según la Normatividad Ambiental vigente y la consignada en la Política de $\mathrm{Hu}$ medales.

Se llevó a cabo la determinación de los indicadores bacterianos con las recomendaciones del Standard Methods for the Examination of Water and Wastewater (8). Se empleó la técnica de Filtración por Membrana. Los medios utilizados para la enumeración de las bacterias indicadoras de contaminación de aguas fueron: Agar Endo para coliformes totales, agar M-FC para Escherichia coli y Agar Azida para Enterococcus spp.

\section{Resultados}

En todos los puntos de muestreo analizados se encontraron recuentos de los tres indicadores, a excepción del punto 8 , ubicado en la zona del parque industrial La Cofradía, en donde no se logró la recuperación de coliformes fecales ni E. coli (ver Tabla 2). 
Tabla 2. Recuento UFC/100mL, muestras de la zona Tres Esquinas, Funza, Cundinamarca.

\begin{tabular}{|c|c|c|c|c|}
\hline \multirow{2}{*}{ ZONA } & \multirow{2}{*}{$\begin{array}{l}\text { PUNTO DE } \\
\text { MUESTREO }\end{array}$} & \multicolumn{3}{|c|}{ RECUENTO EN UFC/100mL } \\
\hline & & Coliformes totales & Escherichia coli & Enterococcus spp. \\
\hline \multirow{7}{*}{ TRES ESQUINAS } & 1 & 9700 & 4700 & 4800 \\
\hline & 2 & 12500 & 4500 & 3300 \\
\hline & 3 & 1600 & 15900 & 7400 \\
\hline & 4 & 1500 & 16700 & 7400 \\
\hline & 5 & 400 & 3600 & 100 \\
\hline & 6 & 3000 & 3500 & 1800 \\
\hline & 7 & 2000 & 4900 & 7400 \\
\hline \multirow{7}{*}{$\begin{array}{c}\text { PARQUE } \\
\text { INDUSTRIAL LA } \\
\text { COFRADÍA }\end{array}$} & 8 & 12500 & 1200 & 18100 \\
\hline & 9 & 0 & 0 & 18100 \\
\hline & 10 & 12500 & 1200 & 18100 \\
\hline & 11 & 12500 & 1200 & 18100 \\
\hline & 12 & 12500 & 1200 & 18100 \\
\hline & 13 & 12500 & 1200 & 18100 \\
\hline & 14 & 12500 & 300 & 18100 \\
\hline
\end{tabular}

En la Figura 1 se observa que en los puntos $1,2,8,10,11,12,13$ y 14 se presentaron los más altos recuentos de coliformes totales. Los puntos 1 y 2 corresponden a la zona de Tres Esquinas y los restantes a la zona del parque industrial La Cofradía. En el punto 9 no se recuperaron coliformes totales. Los recuentos para este indicador están entre 0 y $12500 \mathrm{UFC} / 100 \mathrm{~mL}$.

Figura 1. Recuento de Coliformes totales (UFC/100mL).

\section{Coliformes totales}

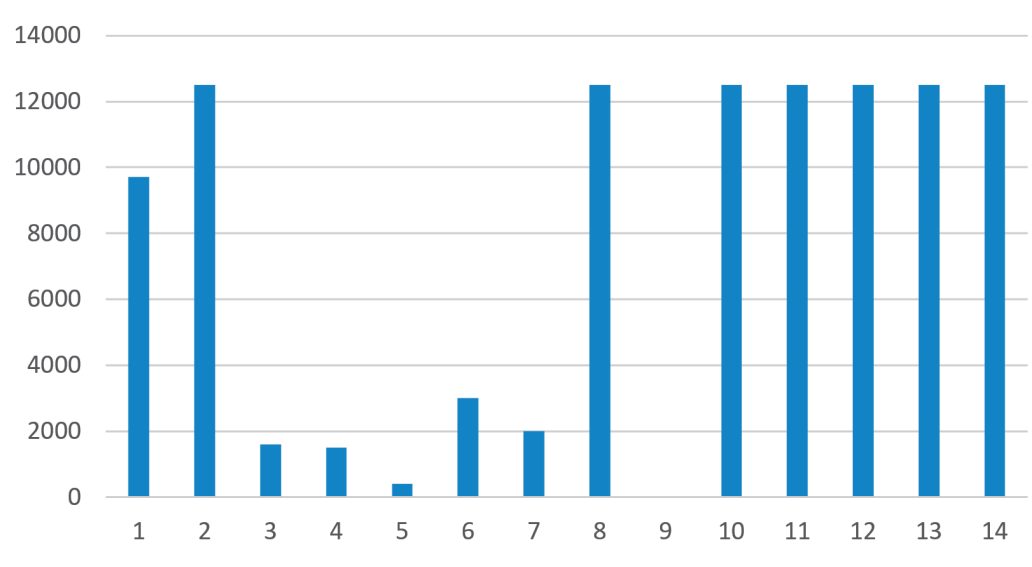


En los puntos 3 y 4 se encontraron los recuentos más altos de Escherichia coli. Estos puntos se localizan en la zona de Tres Esquinas. En la zona del parque industrial La
Cofradía los recuentos obtenidos no superaron las $1200 \mathrm{UFC} / 100 \mathrm{~mL}$ (ver Figura 2). $\mathrm{Al}$ igual que para los coliformes totales, en el punto 9 no se recuperó E. coli.

Figura 2. Recuento de Escherichia coli en UFC/100mL.

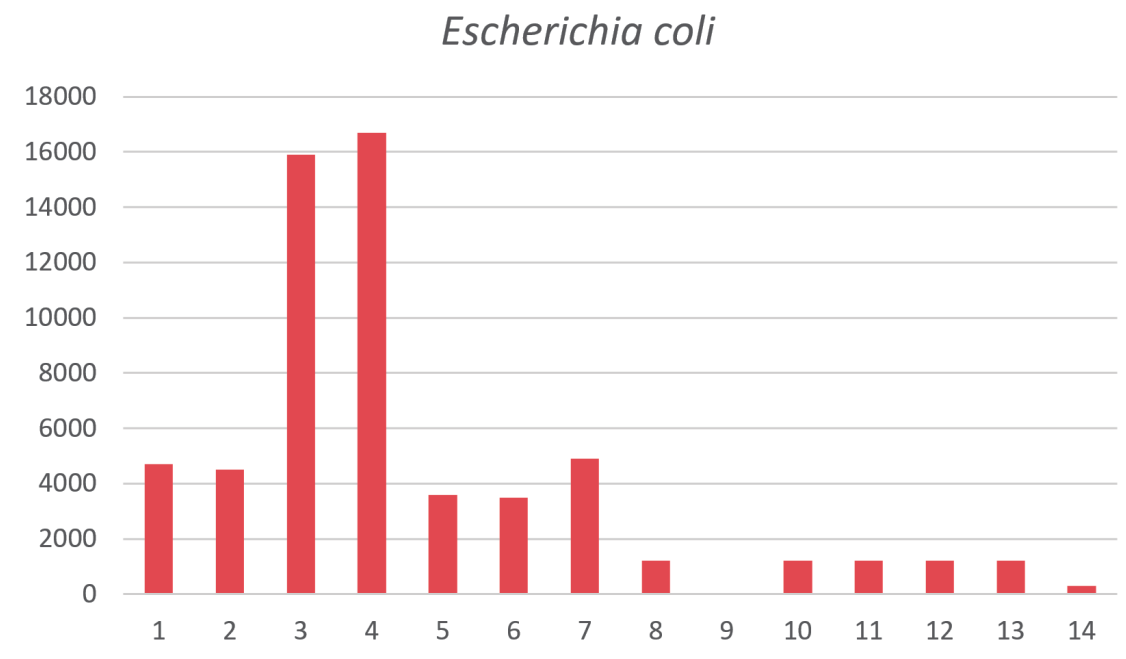

En el caso de Enterococcus spp., en los punUFC/100mL. Este microorganismo se retos $3,4,7,8,9,10,11,12,13$ y 14 se precuperó de todas las muestras recolectadas sentaron los mayores recuentos, los puntos 3 y 4 están en la zona de Tres Esquinas y los demás en el parque industrial La Cofradía. Los recuentos variaron entre 100 y 18100

a diferencia de Escherichia coli y colifomes totales que no tuvieron crecimiento en el punto 9 .

Figura 3. Recuento de Enterococcus spp. en UFC/100 mL.

\section{Enterococcus spp.}

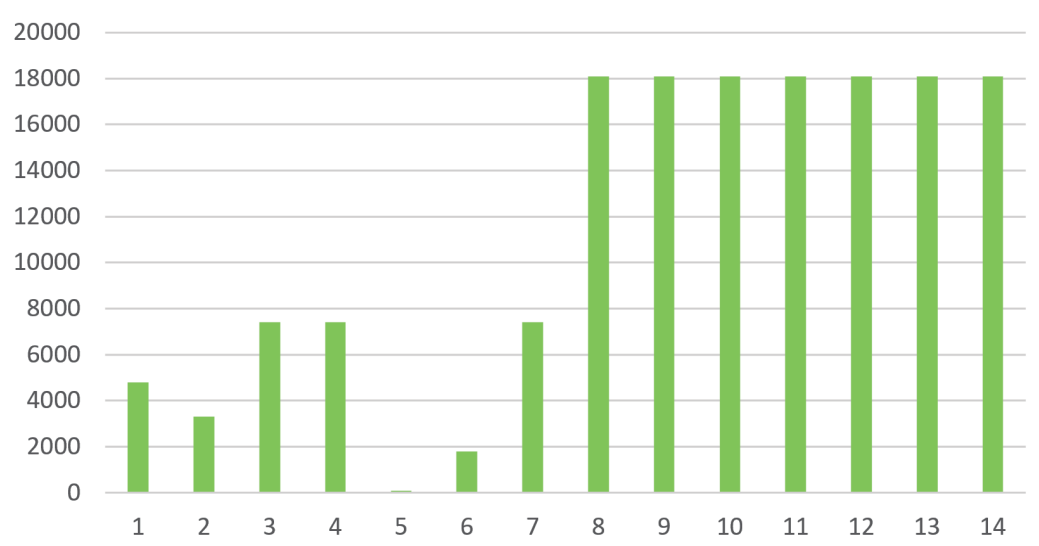


En la Figura 4 se muestra el promedio de los indicadores y se comparan las dos zonas estudiadas. El promedio más alto corresponde a los Enterococcus spp. en la zona del parque industrial La Cofradía, seguido por el de coliformes totales para la misma zona, mientras que para $E$. coli el promedio más alto fue obtenido en la zona de Tres Esquinas.

Figura 4. Promedio de los recuentos bacterianos por zonas.

\section{PROMEDIO DE LOS RECUENTOS BACTERIANOS UFC $/ 100 \mathrm{~mL}$}

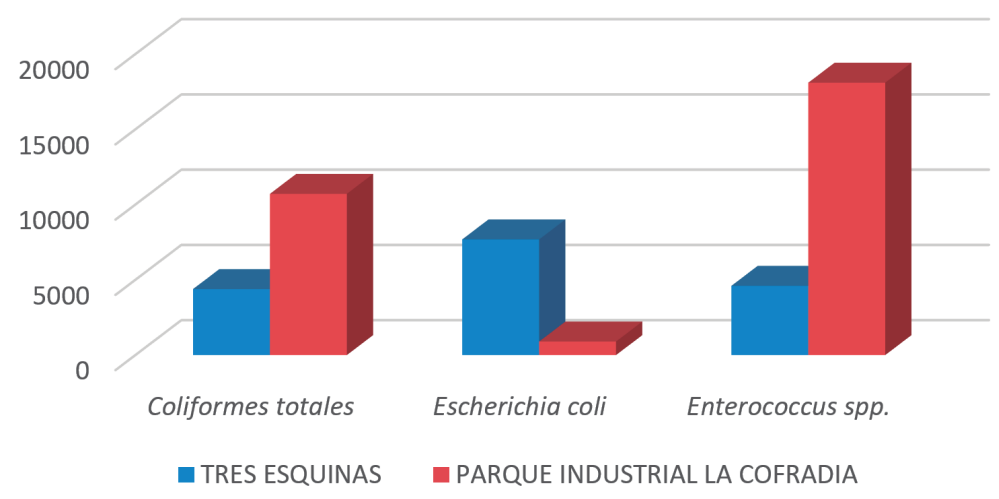

Algunos de los microorganismos aislados que se identificaron mediante pruebas bioquímicas fueron: Escherichia coli, Enterococcus faecium, Klebsiella oxytoca, Citrobacter freundii, Enterobacter cloacae.

\section{Discusión}

Los coliformes totales presentan un elevado recuento en la zona del parque industrial $\mathrm{La}$ Cofradía (a excepción del punto 9), comparados con los obtenidos en la zona de Tres Esquinas. Los altos niveles que se presentan en esta zona pueden deberse al aumento de asentamientos humanos, las actividades antrópicas, las descargas de escorrentía que se realizan por la vía Siberia (9) y la polución que es eliminada al aire por el alto flujo de automóviles (10).

El origen de las bacterias coliformes puede ser fecal o ambiental (mediante insectos, plantas y suelo). Diversos factores ecológicos influyen en su permanencia y sobrevivencia, estas bacterias están adaptadas para vivir en el tracto gastrointestinal, aunque pueden sobrevivir en el agua residual y cuerpos acuáticos (11).

Los altos valores de coliformes totales indican que hay una fuente rica de nutrientes que hace posible que esta comunidad bacteriana esté presente en el cuerpo de agua, posiblemente relacionada a los desagües que llegan al humedal (12). 
Escherichia coli presentó recuentos elevados en la zona de Tres Esquinas, a diferencia de la zona del parque industrial La Cofradía en donde los recuentos no superaron los 1200 UFC/100mL. Chalarca D, Mejía R, Aguirre N. reportan, para la ciénaga de Ayapel, recuentos elevados de Escherichia coli en todos los puntos de muestreo localizados cerca al casco urbano del municipio (13). Estos resultados son similares a los hallados en el humedal Gualí, donde la zona de Tres Esquinas es en la que se presenta un mayor asentamiento de viviendas.

En el punto 9 no se evidenció crecimiento de E. coli a pesar de que se presentaron recuentos de coliformes totales altos. Este fenómeno puede deberse a la menor resistencia de la Escherichia coli a las condiciones medio ambientales, ya que sufren estrés fisiológico, y por esta razón, pierden progresivamente la capacidad de desarrollarse en medios selectivos y diferenciales. Diferentes factores ambientales como la temperatura, la luz solar, la presencia de otras comunidades bacterianas y la composición química del agua repercuten directamente en la mortalidad de estas bacterias intestinales (14).

Los Enterococcus spp., presentan mayores recuentos en los puntos correspondientes a la zona del parque industrial La Cofradía, donde el recuento promedio fue de 18100 $\mathrm{UFC} / 100 \mathrm{~mL}$. Varios estudios han reportado que el aumento de este indicador está relacionado con una fuerte descarga de residuos domésticos de la población y también con la temporada de lluvias ya que generan un ambiente propicio para la reproducción de este microorganismo que tiene una gran capacidad de supervivencia a diferentes factores ambientales (3) (15).

Es importante destacar que Enterococcus $s p p$. en recuentos superiores a $1000 \mathrm{UFC/}$ $\mathrm{mL}$, podrían estar fuertemente relacionados con un alto riesgo de enfermedad gastrointestinal (16), que cobra gran importancia a nivel de salud pública, debido a que el agua de este humedal se utiliza para riego de cultivos de hortalizas y frutales, como uchuvas $y$ fresas (17).

El género de los enterococos fecales tiene mayor permanencia en ecosistemas terrestres contaminados y en ambientes acuáticos que Escherichia coli, ya que no se reproduce en el medio ambiente. Su presencia es de importancia cuando se conoce que existe contaminación fecal y no se manifiestan coliformes, casos en donde las descargas son discontinuas o más viejas, entones mueren los coliformes totales y la Escherichia coli dándole permanencia a los enterococos (18). Estos microorganismos se relacionan con contaminación fecal de origen humano y animal. Se ha confirmado en diferentes análisis que la presencia de diversos animales afecta la calidad bacteriológica de las aguas(19-20).

En conclusión, en el humedal Gualí-Tres Esquinas la presencia de urbanizaciones, industrias, animales domésticos, el pastoreo y el uso del humedal como receptor de aguas 
residuales ha deteriorado de manera significativa la calidad bacteriológica del agua, la zona del parque industrial La Cofradía fue la más contaminada, ya que tuvo recuentos altos para coliformes totales y Enterococcus spp.

\section{Agradecimientos}

Este trabajo fue financiado por la Universidad Colegio Mayor de Cundinamarca y sus autores manifiestan no tener conflicto de intereses.

\section{A la Empresa Municipal de Acueducto, Al- cantarillado y Aseo de Funza EMAAF, por su valioso aporte de información sobre el humedal producto de su experiencia y tra- bajo dedicado en la conservación de este importante recurso natural.}

\section{Referencias}

1. Revueltas Silva O, Córdoba Sánchez N. 2014. Evaluación ambiental del humedal las chozas en el área urbano-rural del municipio de Popayán. [Trabajo de grado]. Universidad de San Buenaventura.

2. Manual de la convención sobre los Humedales Ramsar. 2006. Cuarta edición. http://www.ramsar. org/sites/default/files/documents/pdf/lib/lib_manual2006s.pdf

3. Rodríguez Cuitiva DE. 2012. Distribución de Enterococos como indicadores de contaminación fecal en aguas de la Bahía de Tumaco, Pacífico colombiano. Rev cubana Hig Epidemiol. 50(2). http://scielo.sld. cu/scielo.php?pid=S156130032012000200002\&script=sci_arttext\&tlng=pt
4. Corporación Autónoma Regional de Cundinamarca - CAR. 2011. Humedales del Territorio CAR. Corporación Autónoma Regional de Cundinamarca - CAR. (2014b).

5. Corporación Autónoma regional de Cundinamarca -CAR. 2013. Fundación para la conservación del patrimonio natural - biocolombia, convenio no. 149-03. http://oab.ambientebogota.gov.co/es/ con-la-comunidad/02/fundacion-para-la-conservacion-del-patrimonio-natural-biocolombia

6. DECRETO 475 DE 1998, por el cual se expiden normas técnicas de calidad del agua potable. Ministerio de Salud de Colombia. http://www.emcali. com.co/documents/10157/37675/(11)\%20Decreto++475+de+1998.pdf.

7. Andreu Moliner E. Camacho González A. 2003. Recomendaciones Para la Toma de Muestras de Agua, Biota y Sedimentos en Humedales Ramsar. Madrid. Dirección General de Conservación de la Naturaleza.

8. Lipps W. 2017. Standard Methods for the Examination of Water and Wastewater, 23rd Edition.

9. Suárez López J. 2014.La contaminación de las escorrentías de autopistas como presión significativa sobre las masas de agua. Congreso Nacional De Medio Ambiente 2014. www.conama2014.org

10. Rojas Y, Jordán M, Yegres F, Araujo J. 2013. Caracterización microbiológica del suelo, agua y aire en el humedal Quebrada de Guaranao, Paraguaná, estado Falcón. Revista de la Universidad de Zulia. 4 (9). http://produccioncientificaluz.org/index.php/rluz/ article/view/19671/19626.

11. Barrera-Escorcia G, Fernández-Rendón CL, WongChang I, Ramírez Romero P. 2013. La sensibilidad del grupo coliforme como indicador de la presencia de enterobacterias, patógenas en cuatro cuerpos acuáticos de México. Hidrobiológica 2013, 23 (1): $87-96$

12. Rodríguez R, Retamozo-Chavez R, Aponte H, Valdivia E. 2017. Evaluación microbiológica de un 
cuerpo de agua del ACR humedales de Ventanilla (Callao, Perú) y su importancia para la salud pública local. Ecología Aplicada. 16(1). DOI: http://dx.doi. org/10.21704/rea.v16i1.899

13. Chalarca Rodríguez D, Mejía Ruiz R, Aguirre Ramírez N. 2007. Aproximación a la determinación del impacto de los vertimientos de las aguas residuales domésticas del municipio de Ayapel, sobre la calidad del agua de la ciénaga. Revista Facultad de Ingeniería Universidad de Antioquia. 40. pág. 41-58. http://www.scielo.org.co/scielo.php?pi$\mathrm{d}=$ S012062302007000200003\&script=sci_arttext.

14. Benítez Rodas GA. 2013. Análisis y modelización de la inactivación de Escherichia coli en aguas residuales. https://eprints.ucm.es/22907/1/T34742.pdf

15. López Pérez L, Gómez D‘Angelo Y, Beltrán González J, Alvarez Valiente J. 2013. Indicadores bacteriológicos de contaminación fecal en la Bahía de la Habana. Revista Gestión y Ambiente. 16. (2). http:// www.revistas.unal.edu.co/index.php/gestion/article/view/39564/4203

16. Campos-Pinilla, Cárdenas-Guzmán M, Guerrero-Cañizares A. 2008. Comportamiento de los indicadores de contaminación fecal en diferente tipo de aguas de la sabana de Bogotá (Colombia). Universitas Scientiarum. 13 (2), pp. 103-108

17. Molina Vergel D. 2015. Análisis sobre valoración económica de los servicios ambientales del humedal el Gualí-Tres Esquinas del municipio de Mosquera, Cundinamarca. 9(2), 68-70.

18. Ríos-Tobón S, Agudelo-Cadavid RM, Gutiérrez-Builes LA. 2017. Patógenos e indicadores microbiológicos de calidad del agua para consumo humano. Rev. Fac. Nac. Salud Pública. 35 (2).

19. Namihira-Santillán P, Barrera-Escorcia G, Márquez-García A. 2002. Contaminación por bacterias fecales en el Lago Huayamilpas, México D.F. Hidrobiológica. 12 (2): 129-136. http://www.redalyc.org/ articulo.oa?id=57812205.
20. Sara Lilia, Ávila, Estupiñán Torres, S., Lina Marcela, C., Calderón Cárdenas, X., \& Rubiano Aguirre, W. (2019). Diagnóstico de la calidad bacteriológica del agua del Humedal Córdoba, Bogotá. NOVA, 17(31), 87-95. Recuperado a partir de https://revistas.unicolmayor.edu.co/index.php/nova/article/ view/946 